\title{
Pregnancy Rates Following Transfer of Cultured Versus Non Cultured Frozen Thawed Human Embryos
}

\author{
Bharat Joshi, Manish Banker, Pravin Patel, Preeti Shah and Deven Patel \\ Pulse Women's Hospital, Ahmedabad, Gujarat \\ India
}

\section{Introduction}

Frozen embryo transfers (FET) are increasingly becoming a routine part of in-Vitro Fertilization (IVF) programs at advanced assisted reproductive technology (ART) centers throughout the world. Comparatively FET yield lower pregnancy rates than fresh embryo transfers. Cryopreseravtion offers optimum utilization of embryos produced and is advantageous for the patients with the surplus embryos, ovarian hyper stimulation, radiotherapy or chemotherapy etc. It is of prime importance to dehydrate cells i.e. withdrawal of intracellular water. This is brought about by adding permeable and non permeable cryoprotective agents (CPA). These agents help to minimize the damage to the organelles within the cell and also help to maintain the osmolar changes taking place during the freezing and thawing process. Almost all the cryoprotectants exert some degree of toxic effect to the blastomeres in direct proportion to their concentration used and the time of exposure. The toxic effect can be reduced by step wise addition of cryoprotective agent during the freezing process. Freezing and thawing may damage the morphological characteristics of embryos and survival rate of blastomeres resulting into lower implantation rates. With the varying degrees of post-thaw survival ( $40 \%$ to $90 \%$ ) and success rate (ranging from $7 \%$ to $40 \%$ ) oocytes and embryos have been frozen in almost all developmental stages, e.g. oocyte (Chen,1986, Borini et al, 2004,2006), pronuclear (Barg et al.,1990, Van den Abbeel et al.,1997, Senn et al.,2000 and Al-Hasani et al.,2007), cleavage stage on day2 and day3 post OPU (Li et al.,2007, Mauri et al.,2001, Kuwayama et al.,2005, Van der Elst et al.,1997 and Rama Raju et al., 2005), morula stage (Tao et al.,2001) and blastocyst stage (Menezo,2004, Liebermann and Tucker,2006, Clifford et al.,2007).

\section{Cryopreservation}

Cooling exerts irreversible damage to the cytoplasmic lipid droplets and reversible damage to the microtubules. Further the damages are also shown in intracellular organelles, cytoskeleton and cell-to-cell contacts (Vincent and Jhonson, 1992; Massip et al.,1995; Dobrinsky,1996). Also, due to cooling and thawing process there is fracture damage to the zona pellucida leading to the varying survival of the frozen thawed embryos. As reviewed 
by Guiref et al,2002 and Abdel Hafez et al,2010 various factors affecting outcome are embryo cleavage stage, pre freeze appearance, hormone supplementation during the cycle, ovarian stimulation before Ovum Pick Up (OPU), outcome of fresh Embryo Transfer (ET) cycle, choice of cryoprotective agent, , freezing technique (Controlled rate slow vs Vitrification), type of carrier etc.

\section{Slow freezing}

Slow freezing is a process where embryos are equilibrated in 1-2 mol/1 of permeable and non permeable cryoprotectants, cooled from room temperature to $-7^{\circ} \mathrm{C}$ temperature in a controlled biological freezer, induce seeding at $-7^{\circ} \mathrm{C}$ and than slowly cooled at $0.3-1.0^{\circ} \mathrm{C} /$ minute up to $-35^{\circ} \mathrm{C}$, with a freefall up to $-120^{\circ} \mathrm{C}$. Embryos loaded in straws are plunged in to liquid Nitrogen for storage. Slow freezing causes damage to the embryos due to the intra cellular ice crystal formation but the toxic effect of low concentrations of cryoprotectants favours survival of embryos in slow freezing. This technique is expensive in its requirement of a programmable bio-freezer, liquid Nitrogen consumption, electricity, time of freezing etc. Still this is widely practiced freezing technique in many laboratories around the world.

\section{Vitrification}

Vitrification is the process of solidification of a solution at low temperatures without ice crystal formation, by extreme elevation in its viscosity using cooling rates of 15,000 to $30,000{ }^{\circ} \mathrm{C} / \mathrm{min}$ (Rama Raju et al, 2006). This phenomenon requires either rapid cooling rates (Rall,1987) or the use of high concentration of cryoprotectant solutions, which decrease ice crystal formation and increase viscosity at low temperatures until the molecules become immobilized and has the properties of solid (Fahy,1986). To achieve rapid cooling $\left(2500^{\circ} \mathrm{C} / \mathrm{min}\right)$, the exposure time of embryos to cryoprotectant solutions must be short due to the toxic effects of high cryoprotectant concentrations. However, if the exposure is too short, the penetration of the cryoprotectant will be inadequate and intracellular ice could form, even in the absence of extracellular ice (Otoi et al.,1998). The way to circumvent the noxious effects of cryoprotectants in the vitrification process could be through the use of high cryoprotectant concentrations for short periods of time (Vajta et al.,1998) or increasing the equilibration period by using lower cryoprotectant concentrations (Papis et al.,2000).

With the advances made in cryobiology by using combinations of freezing solution or/and thawing techniques there is an improvement in the pregnancy rates. This was extensively reviewed in a meta-analysis by Abdel Hafez et al, 2010 suggesting superiority of vitrification technology over slow freezing method in terms of significantly higher survival rate of embryos with an increased implantation and pregnancy rates. In terms of techniques employed for freezing, vitrification is gaining more and more support over slow freezing.

However, at our center vitrification has just been introduced and still in trial phase. Simultaneously we are putting in efforts to investigate factors which may enhance pregnancy rates using slow freezing with the aim to select embryos after freezing and thawing so as to get similar results as obtained by using fresh embryos. 


\section{Materials and methods}

\subsection{Embryo freezing and thawing at Pulse}

With the aim to improve upon pregnancy rates (PR) and to get better selection of embryos from thawed embryos (culture vs non culture), a retrospective analysis of work done at Pulse Women's Hospital, Ahmedabad, India during 2006-2011 is presented here. Patients opting for ART procedure were stimulated using long or antagonist protocols. Ovulation was triggered when majority of the follicles attained $18-20 \mathrm{~mm}$ diameter with human Chorionic Gonadotropin (hCG). Mature oocytes were inseminated within 4 hours of collection. Fertilization checks were carried out 16-20 hours post insemination. Not more than three embryos were transferred $\sim 48$ hours post egg collection. Surplus embryos were frozen in Embryo Freezing Media (Cook Medicals, Australia) using Cryologic programmable biofreezer (CL 8800$)$ in mini straws $(0.25 \mathrm{ml}$ capacity). Seeding was induced at $-7^{\circ} \mathrm{C}$ followed by cooling with the rate $-0.3^{\circ} \mathrm{C} /$ minute up to $-35^{\circ} \mathrm{C}$ with a free fall to $120^{\circ} \mathrm{C}$. Thereafter the straws were stored in liquid Nitrogen. Embryos were thawed either on the ET day or a day prior to ET. Thawing was performed with stepwise removal of CPA using Embryo Thawing Media (Cook Medicals, Australia).

\subsection{Results and discussion}

Data created during 2006-2011 were analyzed using Chi-Square test. Out of total 1248 frozen thaw ET cycles, 275 pregnancies (PR-22.0\%) were obtained, similar to the $28.8 \%$ pregnancy rates obtained by Ying-hui et al, 2002. Results were compared for parameters like patient's age, number of embryos transferred and the time interval between thawing and transfer.

\subsection{Patient's age}

Comparing the age of patient (Table:1), up to 30 years resulted in $25.4 \%$ pregnancy rates which is significantly higher than the $18.6 \%$ rates obtained in patients with the age of $>30$ years $(\mathrm{p}<0.01)$.

\begin{tabular}{|c|c|c|c|}
\hline $\begin{array}{c}\text { Patient's } \\
\text { AGE }\end{array}$ & $\begin{array}{c}\text { No. of } \\
\text { ET'S }\end{array}$ & PREGNANT & $\begin{array}{c}\text { PREGNANCY } \\
\text { RATE (\%) }\end{array}$ \\
\hline$\leq 30$ & 630 & 160 & 25.4 \\
\hline$>30$ & 618 & 115 & 18.6 \\
\hline
\end{tabular}

Table 1. Pregnancy rates according to patient's age

\subsection{Number of embryos transferred}

FET of 3 embryos yielded $27.1 \%$ pregnancy rates, significantly higher to the $9.9 \%$ pregnancy rates (Table:2) obtained when upto 2 embryos were transferred $(\mathrm{p}<0.0003)$. 


\begin{tabular}{|c|c|c|c|}
\hline NO OF EMBRYOS & No. of ET & $\begin{array}{c}\text { No. of } \\
\text { pregnancy }\end{array}$ & $\begin{array}{c}\text { PREGNANCY } \\
\text { RATE (\%) }\end{array}$ \\
\hline$\leq 2$ & 365 & 36 & 9.9 \\
\hline 3 & 883 & 239 & 27.1 \\
\hline
\end{tabular}

Table 2. Pregnancy rates according to number of embryos transferred

\subsection{Time interval between thawing and transfer}

Data were further divided into two groups viz. group I in which embryos were thawed and cultured overnight before ET and group II in which embryos were thawed and transferred within two hours (Table: 3 ).

\begin{tabular}{|c|c|c|c|c|}
\hline GROUP & MEAN AGE & $\begin{array}{c}\text { No. of } \\
\text { pregnancy/ ET }\end{array}$ & PREGNANCY & $\begin{array}{c}\text { PREGNANCY } \\
\text { RATE (\%) }\end{array}$ \\
\hline $\begin{array}{c}\text { I } \\
\text { (Overnight culture) }\end{array}$ & 31.6 yrs. & 1074 & 240 & 22.3 \\
\hline $\begin{array}{c}\text { II } \\
\text { (2 hours culture) }\end{array}$ & 30.1 yrs. & 174 & 35 & 20.1 \\
\hline
\end{tabular}

Table 3. Pregnancy rates according to time of ET

Embryos cultured overnight produced pregnancy rates of $22.3 \%$ while embryos transferred within 2 hours post thawing resulted in pregnancy rates of $20.1 \%$, showing no significant difference between the two groups. Results are comparable with the pregnancy rates obtained by Karlstorm et al, 1997 (22\%) and by Singh et al,2007 (16\%).

Van der Elst et al,1997, Zeibe et al,1998 and Guiref et al,2002 proposed to evaluate resumption of mitosis by doing overnight culture and selection of thawed embryos before transfer. On this basis within group I i.e. the cultured group, embryos were assessed for further cleavage of the blastomeres. There was a significant difference $(p<0.0001)$ when all non-cleaved embryos were transferred $(7.1 \%)$ and when 1 to 3 cleaved embryos $(31.9 \%)$ were transferred (Table:4). This is similar to the results obtained by Ying-hui et al,2002, where $35.2 \%$ pregnancy rate was achieved when at least one cleaved embryo was transferred against $10.2 \%$ when no cleaved embryo was transferred. Further pregnancy rates were significantly higher when two $(p=0.0004)$ and three $(p=0.0005)$ cleaved embryos were transferred compared to only one cleaved embryo. However, there was no significant difference between transfer of two and three cleaved embryos. 


\begin{tabular}{|c|c|c|c|c|}
\hline $\begin{array}{c}\text { EMBRYOS } \\
\text { CLEAVED }\end{array}$ & ET & PREGNANCY & $\begin{array}{c}\text { PREGNANCY } \\
\text { RATE (\%) }\end{array}$ & p values \\
\hline 0 & 294 & 21 & $7.1^{\mathrm{a}}$ & $\begin{array}{c}<0.0001 \\
\mathrm{a} . \mathrm{b}\end{array}$ \\
\hline 1 & 422 & 83 & $19.7 \mathrm{~b}$ & $\begin{array}{c}=0.0004 \\
\mathrm{~b}, \mathrm{c}\end{array}$ \\
\hline 2 & 258 & 93 & $36.1^{\mathrm{c}}$ & $\begin{array}{c}=0.0005 \\
\mathrm{~b}, \mathrm{~d}\end{array}$ \\
\hline 3 & 100 & 43 & $43^{\mathrm{d}}$ & $\mathrm{c}$ \\
\hline
\end{tabular}

Table 4. Comparison of pregnancy rate between numbers of cleaved embryos transferred

When 2 cleaved embryos after culture were transferred, $36.1 \%$ pregnancies were achieved and when all 3 cultured and cleaved embryos were transferred, $43.0 \%$ pregnancy rates were achieved, showing that these results are at par with those obtained in fresh embryo transfer cycle. This is much higher than the results obtained by Karlstorm et al,1997, where pregnancy rates was $23 \%$ when 2 cleaved embryos were transferred and $27 \%$ when 3 cleaved embryos were transferred.

Pregnancy rates have shown further increase when only the embryos which have cleaved to an eight cell stage during culture were transferred (Table:5) as compared to results shown in table 4 .

\begin{tabular}{|c|c|c|c|c|}
\hline $\begin{array}{c}\text { EMBRYOS } \\
\text { CLEAVED } \\
\text { (only 8 cells) }\end{array}$ & ET & PREGNANCY & $\begin{array}{c}\text { PREGNANCY } \\
\text { RATE (\%) }\end{array}$ & P values \\
\hline 0 & 294 & 21 & $7.1^{\mathrm{a}}$ & \\
\hline 1 & 302 & 67 & $22.2^{\mathrm{b}}$ & $<0.0001 \mathrm{a}, \mathrm{b}$ \\
\hline 2 & 208 & 84 & $40.4^{\mathrm{c}}$ & $<0.001 \mathrm{~b}, \mathrm{c}$ \\
\hline 3 & 82 & 38 & $46.3^{\mathrm{d}}$ & $<0.003 \mathrm{~b}, \mathrm{~d}$ \\
\hline
\end{tabular}

Table 5. Comparison of pregnancy rate when only 8-cell embryos were transferred

Highly significant difference $(\mathrm{p}<0.0001)$ in pregnancy rates was observed when all noncleaved embryos were transferred compared to 1 to 3 cleaved 8-celled embryos. Pregnancy rates were significantly higher when two $(p<0.001)$ and three $(p<0.003)$ cleaved 8 - celled embryos were transferred compared to only one cleaved 8- celled embryo. However, there was no significant difference between transfer of two and three cleaved 8-celled embryos. 


\section{Conclusion}

Taking into account the results obtained in various categories it can be concluded that pregnancy rates can be improved through selection of better embryos and brought at par with that of fresh ET.

\section{References}

[1] Chen, C. (1986) Pregnancy after human oocyte cryopreservation. Lancet 1, 884-886.

[2] Borini, A., Bonu M.A., Coticchio. G., Bianchi, V., Cattoli, M and Flamigni, C. (2004) Pregnancies and births after oocyte cryopreservation. Fertility and sterility, 82, 601-605.

[3] Borini, A., Sciajno, R., Bianchi, V., Sereni, E, Flamigni, C. and Coticchio. G., (2006) Clinical outcome of oocyte cryopreservation after slow cooling with a protocol utilizing a high sucrose concentration. Human Reproduction, 21, 512-517.

[4] Barg, P.E., Barad, D.H. and Feichtinger, W. (1990). Ultrarapid freezing (URF) of mouse and human preembryos: a modified approach. J. In vitro Fertil. Embryo Transfer IVF 7, 355-357.

[5] Van den Abbeel, E., Camus, M., Van Waesberghe, L., et al., (1997) A randomized comparison of the cryopreservation of one-cell human embryos with a slow controlled-rate cooling procedure or a rapid cooling procedure by direct plunging into liquid nitrogen. Human Reproduction Vol.12, pp-1554-1560.

[6] Senn, A., Vozzi, C., Chanson, A., et al. (2002) Prospective randomized study of two cryopreservation policies avoiding embryo selection: the pronucleate stage leads to a higher cumulative delivery rate than the early cleavage stage. Ferti. Steril. 74, 946-952.

[7] Al-Hasani, S., Ozmen, B., Koutlaki, N., et al (2007) Three years of routine vitrification of human zygotes: is it still fair to advocate slow-rate freezing? Reproductive BioMedicine Online 14, 288-293.

[8] Li, Y., Chen, Z.J., Yang, H.J, et al, (2007) Comparison of vitrification and slow freezing of human day 3 cleavage stage embryos: post vitrification development and pregnancy outcomes. Zhonghua Fu Chan Ke Za Zhi, 42, 753-755.

[9] Mauri, A.L., Petersen, C.G., Baruffi, R.L., et al., (2001) Comparison of the cryopreservation of human embryos obtained after intracytoplasmic sperm injection with a slow cooling or an ultrarapid cooling procedure. J. Assist. Reprod. Genet. 18, 257-261.

[10] Kuwayama, M., Vajta, G., Ieda, S., Kato, O., (2005) Comparison of open and closed methods for vitrification of human embryos and the elimination of potential contamination. Reproductive BioMedicine Online. Vol 11, pp-608-614.

[11] Van der Elst, J., Van den Abbeel, E., Vitrier, S., Camus, M., Devroey P. and Van Steirteghem, A.C. (1997) Selective transfer of cryopreserved human embryos with further cleavage after thawing increases delivery and implantation rates. Human Reproduction. Vo. 12, pp-1513-1521. 
[12] Rama Raju, G.A., Haranth, G.B., Krishana, K.M., Jaya Prakash, G. and Madan, K. (2005) Vitrification of human 8-cell embryos, a modified protocol for better pregnancy rates. Reproductive BioMedicine Online, Vol 11, 434-437.

[13] Tao. J., Tamis, R., Fink, K., (2001) Pregnancies achieved after transferring frozen morula/ compact stage embryos. Fertility and Sterility, 75, 629-631.

[14] Menezo, Y., (2004) Cryopreservation of IVF embryos: which stage? Eur. J. Obstet. Gynecol. Reprod. Biol. 113, (Suppl. 1) S28-S32.

[15] Liebermann, J., and Tucker, M.J., (2006) Comparison of vitrification and conventional cryopreservation of day 5 and day 6 blastocysts during clinical application. Fertility and Sterility, 86, pp- 20-26.

[16] Clifford, A.L., Jilbert, P.M., Gentry, W.L., et al., (2007) Better ongoing pregnancy rates from frozen embryo transfers when vitrified blastocysts are used. Fertility and Sterility. 88 (Suppl. 1), S349-S350.

[17] Vincent, C. and Jhonson, J.H. (1992) Cooling cryoprotectants and the cytoskeleton of the mammalian oocyte. Oxford Review in Reproductive Biology, 14, 73-100.

[18] Massip, A., Mermillod, P., Dinnyes, A. (1995) Morphology and biochemistry of in-vitro produced bovine embryos: implications for their cryopreservation. Human Reproduction, 10, 3004-3011.

[19] Dobrinsky, J.R. (1996) Cellular approach to cryopreservation of embryos. Theriogenology, 45, 17-26.

[20] Guiref, F., Bidault, R., Cadoret, V., Couet, M., Lansac, J and Royere D. (2002) Parameters guiding selection of best embryos for transfer after cryopreservation: a reappraisal. Human Reproduction Vol.17, No.5 PP. 1321-1326.

[21] Abdel Hafez, F.F., Desai, N, Abou-setta, A.M. Falcone T and Goldfarb J. (2010) Slow freezing, vitrification and ultra-rapid freezing of human embryos: a systematic review and meta analysis.

[22] Rama Raju G A, Murali Krishna K, Prakash G J and Madan K. 2006. Vitrification: An emerging Technique for Cryopreservation in Assisted Reproduction Programmes. Embryo Talk Vol 1.4 : 210- 227.

[23] Rall W F. 1987. Factors affecting the survival of mouse embryos cryopreserved by vitrification. Cryobiology 24, 387-402.

[24] Fahy G M. 1986. vitrification: a new approach to organ cryopreservation. In:Meryman HT (ed.), Transplantation: approaches to graft rejection, Alan R Liss, New york, PP: 305-355.

[25] Otoi T, Yamamoto K, Koyama N, Tachikawa S, Suzuki T. 1998, Cryopreservation of mature bovine oocytes by vitrification in straws. Cryobiology. Aug;37 (1):77-85.

[26] Vajta G, Holm P, Kuwayama M, Booth P J, Jacobsen H, Greve T, Callesen H. 1998. Open pulled straw vitrification: a new way to reduce cryoinjuries of bovine ova and embryos. Mol Reprod Dev. 51: 53-58.

[27] Papis K, Shimizu M, Izaike Y. 2000. Factors affecting the survivability of bovine oocytes vitrified in droplets. Theriogenology. Sep 15;54(5):651-8.

[28] Ying-hui, Y.E., Fan, J.I.N., Chen-ming, X.U.,Lan-feng, X.I.N.G, (2002) Factors influencing the outcome of embryo freezing and thawing program. Journal of Zhejiang University Science V.3.pp-493-496 
[29] Karlstorm, P.O., Bergh, T., Forsberg, A.S. Sandkvist, U., Wikland, M. (1997) Prognostic factors for the success rate of embryo freezing. Human Reproduction. Vol 12, pp1263-1266.

[30] Singh, P.M., Vrotson, K., Balen, A.H., (2007) Frozen embryo replacement cycle: An analysis of factors influencing the outcome. J. Obstet Gynecol India. Vol 57, pp240-244.

[31] Zeibe, S., Bech, B., Petersen, K., et al., (1998) Resumption of mitosis during post-thaw culture: a key parameter in selecting the right embryos for transfer. Human Reproduction. Vol 13, pp-178-181. 


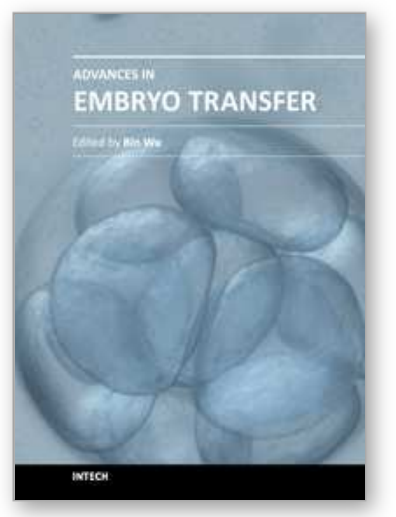

\author{
Advances in Embryo Transfer \\ Edited by Dr. Bin Wu
}

ISBN 978-953-51-0318-9

Hard cover, 248 pages

Publisher InTech

Published online 14, March, 2012

Published in print edition March, 2012

Embryo transfer has become one of the prominent high businesses worldwide. This book updates and reviews some new developed theories and technologies in the human embryo transfer and mainly focus on discussing some encountered problems during embryo transfer, which gives some examples how to improve pregnancy rate by innovated techniques so that readers, especially embryologists and physicians for human IVF programs, may acquire some new and usable information as well as some key practice techniques. Major contents include the optimal stimulation scheme for ovaries, advance in insemination technology, improved embryo transfer technology and endometrial receptivity and embryo implantation mechanism. Thus, this book will greatly add new information for readers to improve human embryo transfer pregnancy rate.

\title{
How to reference
}

In order to correctly reference this scholarly work, feel free to copy and paste the following:

Bharat Joshi, Manish Banker, Pravin Patel, Preeti Shah and Deven Patel (2012). Pregnancy Rates Following Transfer of Cultured Versus Non Cultured Frozen Thawed Human Embryos, Advances in Embryo Transfer, Dr. Bin Wu (Ed.), ISBN: 978-953-51-0318-9, InTech, Available from:

http://www.intechopen.com/books/advances-in-embryo-transfer/pregnancy-rates-following-transfer-ofcultured-versus-non-cultured-frozen-thawed-human-embryos

\section{INTECH}

open science | open minds

\author{
InTech Europe \\ University Campus STeP Ri \\ Slavka Krautzeka 83/A \\ 51000 Rijeka, Croatia \\ Phone: +385 (51) 770447 \\ Fax: +385 (51) 686166 \\ www.intechopen.com
}

\author{
InTech China \\ Unit 405, Office Block, Hotel Equatorial Shanghai \\ No.65, Yan An Road (West), Shanghai, 200040, China \\ 中国上海市延安西路65号上海国际贵都大饭店办公楼 405 单元 \\ Phone: +86-21-62489820 \\ Fax: +86-21-62489821
}


(C) 2012 The Author(s). Licensee IntechOpen. This is an open access article distributed under the terms of the Creative Commons Attribution 3.0 License, which permits unrestricted use, distribution, and reproduction in any medium, provided the original work is properly cited. 